\title{
Recurrent laryngeal inflammatory myofibroblastic tumor with positive anaplastic lymphoma kinase mimicking recurrent respiratory papillomatosis: a case report
}

\author{
Chun-yan He, Ge-hong Dong and Hong-gang Liu*
}

\begin{abstract}
Inflammatory myofibroblastic tumor (IMT) of the larynx is an unusual lesion, particularly in the pediatric age group. Laryngeal IMTs in children follow a benign clinical course with reports of only rare recurrences and no metastases. Although anaplastic lymphoma kinase (ALK) has been associated with IMTs, there is only one pediatric laryngeal IMT reported to be ALK-positive with immunohistochemical staining. Here, we present a case of a 10-year-old boy with a laryngeal IMT that recurred four times and was misdiagnosed as recurrent respiratory papillomatosis after the initial three operations. ALK positivity was demonstrated by both immunohistochemical staining and fluorescence in situ hybridization. To the best of our knowledge, this case report is the first to describe a laryngeal IMT that recurred multiple times and was confirmed to be ALK-positive at the molecular level.
\end{abstract}

Keywords: Inflammatory myofibroblastic tumor, Larynx, Pediatric, ALK

\section{Background}

Inflammatory myofibroblastic tumor (IMT) is an uncommon lesion that usually involves the lungs and mostly affects young adults [1,2]. In the head and neck region, the paranasal sinuses and orbit are the most commonly affected areas [3]. The laryngeal presentation is extremely rare; about 30 cases have been described in the literature in English and only eight of these involved children [4-11]. Among these eight IMTs, there is only one case of recurrence after resection [7], demonstrating the benign clinical behavior of this tumor. In addition, although anaplastic lymphoma kinase $(A L K)$ gene translocation can be seen in about $50 \%$ of IMTs in young patients $[2,12]$, there is only one case of childhood laryngeal IMT that reported ALK-1 positivity by immunohistochemical staining [4]. So far, there are no reports of $A L K$ gene translocation detected at the molecular level in laryngeal IMTs.

\footnotetext{
*Correspondence: liuhg1125@163.com

Department of Pathology, Beijing Tongren Hospital, Capital Medical University, No.1 Dongjiaominxiang Street, Dongcheng District, Beijing 100730, China
}

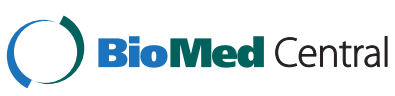

(c) 2014 He et al.; licensee BioMed Central Ltd. This is an Open Access article distributed under the terms of the Creative Commons Attribution License (http://creativecommons.org/licenses/by/2.0), which permits unrestricted use, distribution, and reproduction in any medium, provided the original work is properly credited. The Creative Commons Public Domain Dedication waiver (http://creativecommons.org/publicdomain/zero/1.0/) applies to the data made available in this article unless otherwise stated.
Here, we present a case of a laryngeal IMT in a 10-yearold boy. It recurred four times and was misdiagnosed as recurrent respiratory papillomatosis (RRP) after the initial three operations. ALK positivity was demonstrated by both immunohistochemical staining and fluorescence in situ hybridization (FISH). Despite the excellent prognosis of laryngeal IMTs, this case presented a clinical and surgical challenge in the form of multiple recurrences, due mainly to incomplete tumor resection.

\section{Case presentation}

A 10-year-old boy was referred to a local hospital with hoarseness for 1 year in July 2009. Clinicians saw a tumor of the vocal cord, which subsequently was resected by using direct microlaryngoscopy with a carbon dioxide $\left(\mathrm{CO}_{2}\right)$ laser. Respiratory papilloma was diagnosed after pathologic analysis. After the procedure, the symptom of hoarseness actually worsened and the patient also gradually developed a foreign body sensation. He then presented to our hospital in May 2010. Fibrolaryngoscopy demonstrated exophytic masses involving the whole length of the right vocal cord and extending to the anterior commissure and anterior third of the left 
vocal cord (Figure 1). The cords were mobile, and no cervical lymphadenopathy was appreciated on palpation. In addition, there was no recent history of fever or weight loss, and laboratory findings were normal. The tumor was resected by using direct microlaryngoscopy with a $\mathrm{CO}_{2}$ laser, and histological examination was performed (see below).

Six months after the second operation, the patient was referred again for hoarseness in addition to shortness of breath. Via laryngoscopy, similar exophytic masses were observed at the same location, and these masses were then resected. However, the lesion returned 5 months later and was removed again, only to reappear a fourth time after 2 months. The tumor from the fourth operation showed a proliferation of spindle cells in the subepithelial stroma. A diagnosis of IMT was made after reviewing the histopathology, combined with the results of immunohistochemical staining and testing for human papillomavirus (HPV) and ALK. During a clinical and pathological discussion, it was proposed that incomplete resection was the cause of tumor relapse. A fifth operation was performed, and frozen sections of the surgical margins sent at the time of the procedure were all negative for IMT. The child's voice improved after 3 months, and the tumor failed to recur during 2 years of regular follow-up. This report was approved by the hospital ethics committee, and written informed consent for publication of the clinical details and clinical image was obtained from the patient's guardian.

All histologic sections from the five operations were reviewed. Because the primary lesion and the recurrences had similar histological and immunohistochemical features, they are described together. Microscopically, the lesions displayed an exophytic, polypoid, and papillary appearance under low power (Figure $2 \mathrm{~A}$ ) with a hyperplastic

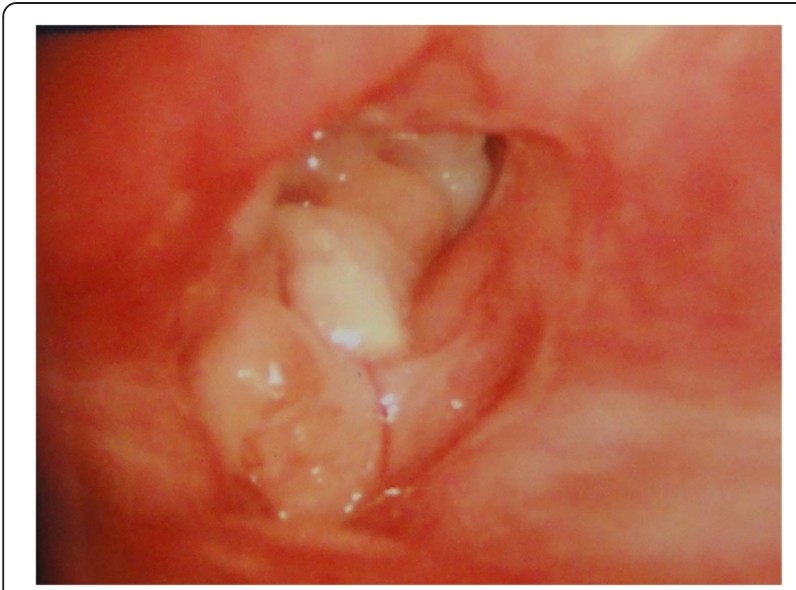

Figure 1 Laryngoscopic view. Exophytic masses involved the whole length of the right vocal cord and reached the anterior commissure and front of the left vocal cord. squamous epithelial lining. In this squamous lining, there appeared to be koilocyte-like cells. The subepithelium consisted of fibrovascular cores. Most of the cores were large and compact with obvious hyperplasia of spindle cells (Figure 2B), unlike the fibrovascular cores of squamous papillomas, which are thin and loose. The hyperplasia of stromal cells was more obvious in the last two specimens because the sections from the first three operations were relatively superficial. The spindle cells were arranged in both a fascicular and storiform pattern with lymphocytes and plasma cells in the background (Figure $2 \mathrm{C}$ ). The spindle cells contained pale, eosinophilic cytoplasm and nuclei that were elongated and slightly pleomorphic with one or more small nucleoli (Figure 2D). Occasional regular mitoses (about 0.8 per 10 high-powered fields) and some ganglion-like cells could be seen, and necrosis was absent. Immunohistochemically, the squamous epithelium was negative for P16. The spindle cells were positive for vimentin, smooth muscle actin, and ALK-1 (Figures 3A-C) but negative for desmin, muscle-specific action, S-100, Bcl-2, CD34, cytokeratin, and $\mathrm{p} 53$. The Ki-67 proliferation index was about $3 \%$.

We applied in situ hybridization as well as polymerase chain reaction analysis to test for the HPV genotype. The two analyses included HPV types 6, 11, 16, 18, 31, $33,35,39,42,43,44,45,51,52,53,58,59,66,68$, and CP8304. The viral tests did not demonstrate any of the above-mentioned HPV types. We performed FISH with Vysis LSI ALK Dual-Color, Break-Apart Rearrangement Probe (Abbott Molecular, Abbott Park, IL, USA) on the spindle cells and found translocations involving the $A L K$ locus (Figure 3D). On the basis of the histopathological and immunohistochemical features and the result of the FISH test, a diagnosis of IMT was rendered.

\section{Discussion}

IMT involving the larynx is rare, especially in the pediatric age group. To date, only eight cases of childhood laryngeal myofibroblastic lesions have been reported in the literature in English: four cases diagnosed as IMT and four as inflammatory pseudotumor (IPT) [4-11]. The mean age of these patients is 5.7 years (range of 2.5 to 10 years), and the male-to-female ratio is $7: 1$. Dyspnea and stridor are the most frequently reported symptoms, whereas hoarseness (which is more common in adult laryngeal IMTs) is seen in only two cases, who are relatively older. The mean symptom duration is 3.9 months (range of 0.5 to 6 months) [4-11]. Most cases generally involve the subglottic region, and only one involved the vocal cord. The majority of the lesions are nodular or polypoid, and one case mimicked papillomatosis [5]. The lesions rarely recur after tumor resection, showing benign behavior, except for one report of a 

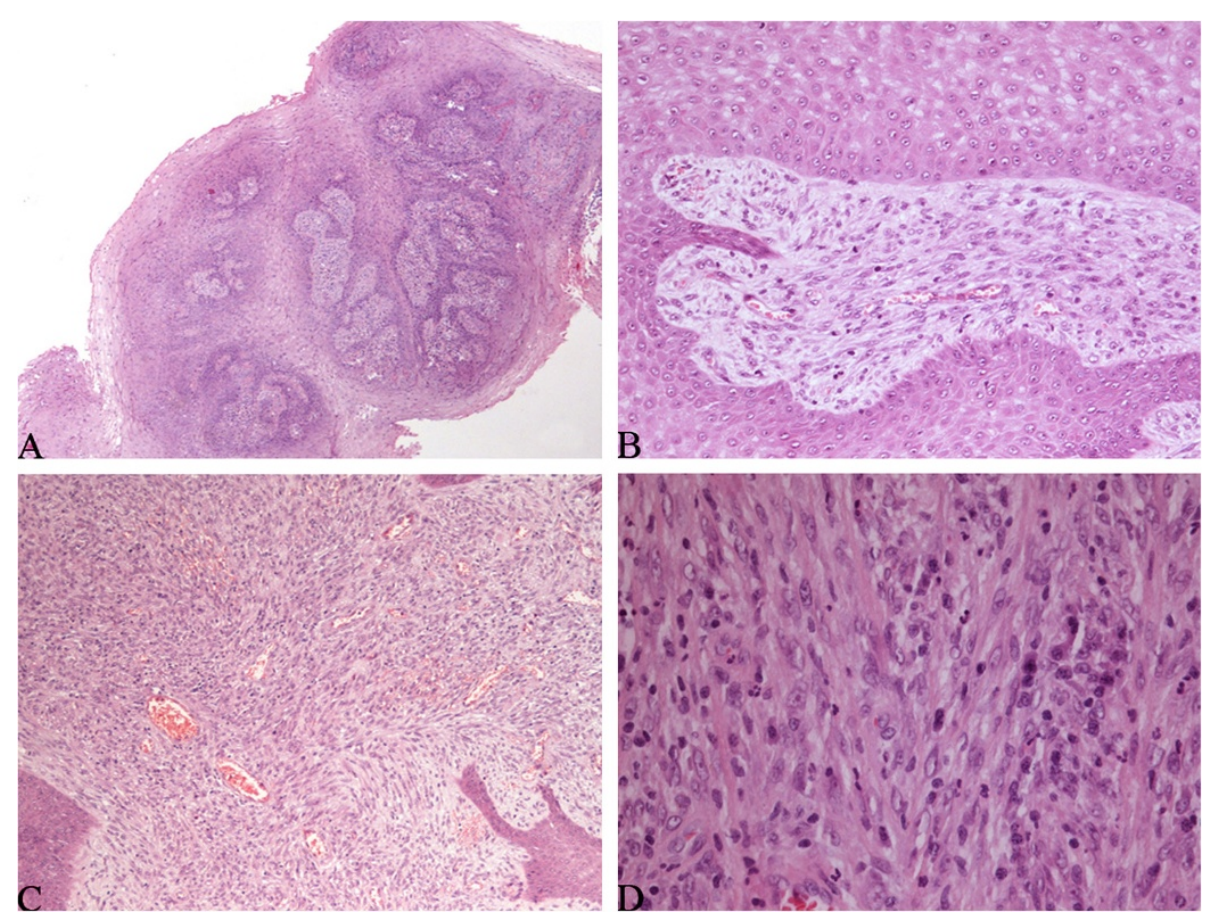

Figure 2 Histological findings. (A) The lesions displayed a papillary and polypoid appearance (hematoxylin-eosin [HE] $\times$ 40). (B) There was obvious spindle cell hyperplasia in the fibrovascular cores $(\mathrm{HE} \times 200)$. (C) The spindle cells were arranged in both a fascicular and storiform pattern with lymphocytes and plasma cells in the background (HE $\times$ 100). (D) The spindle cells contained pale, eosinophilic cytoplasm and elongated nuclei with one or more small nucleoli $(\mathrm{HE} \times 400)$.
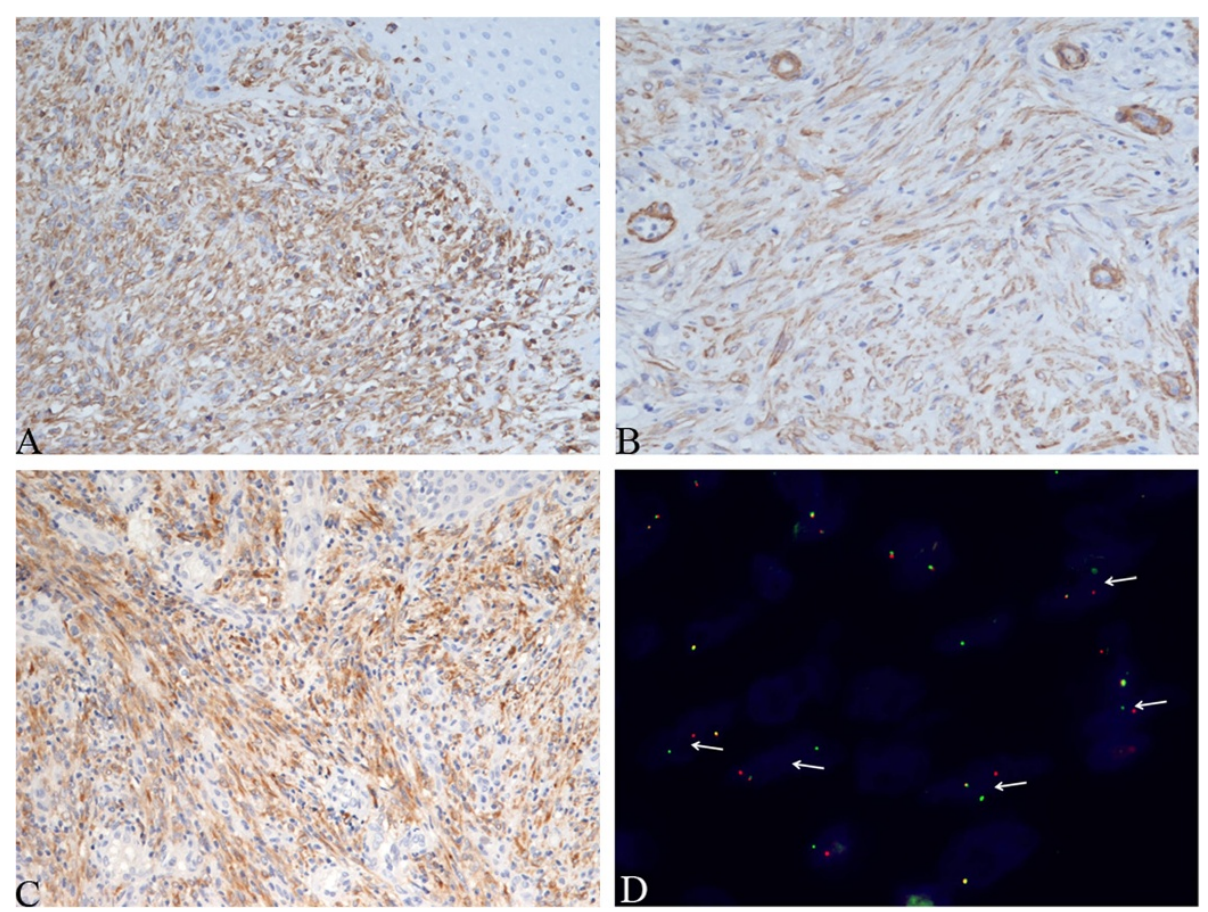

Figure 3 Immunohistochemical findings and fluorescence in situ hybridization (FISH) studies. The spindle cells were positive for vimentin (A), a-smooth muscle actin (B), and anaplastic lymphoma kinase-1 (ALK-1) (C) (immunohistochemistry staining $\times 200$ ). (D) FISH studies demonstrated rearrangements of the ALK gene with split of the red and green signals (arrows) in the spindle cells. 
single recurrence after an incomplete resection [7]. Our patient was a 10 -year-old boy with hoarseness for 1 year. The lesion was located in the vocal cord, had a polypoid and papillary appearance, and recurred four times. We believe that the relatively superficial resections of the initial surgeries and the wrong pathological diagnosis were the reasons behind the multiple recurrences. The histological features that led to the incorrect diagnosis of papilloma included papillary growth, squamous epithelial hyperplasia with mild atypia, and koilocyte-like cells within the epithelium (although results of HPV-related tests were negative). The clinical diagnosis of RRP led the otolaryngologists to neglect the surgical margins.

The etiology of IMT is still controversial. Viruses that are suspected to be involved in the development of IMT include human herpesvirus-8 (HHV-8) and Epstein-Barr virus (EBV), as reported in cases of adult pulmonary, splenic, and hepatic IMTs $[13,14]$. There is no report of HHV-8- or EBV-positive laryngeal IMTs in adults or children. IgG4-related disease is a recently described multisystem disorder [15] that may also be associated with IMT. The disease is characterized histologically by an infiltrate of plasma cells, which is similar to inflammatory myofibroblastic tumors [16]. However, only a single IgG4-positive laryngeal IMT has been reported (in a 56-year-old man) [17] and none in children. A physical cause of laryngeal IMT has been proposed by multiple reports. Trauma or potential subclinical traumatic stimuli such as voice abuse, excessive coughing, and acid-reflux are often associated with wound healing, which includes the presence of myofibroblasts. Several laryngeal IMT reports suggest that trauma or subclinical trauma may be one etiology of IMT [17-19]. However, there are scholars who argue that trauma-induced myofibroblastic proliferative lesions should be diagnosed as IPT, which is a reactive hyperplasia, rather than IMT-a true neoplasm [20]. The terms IPT and IMT of the larynx are still used interchangeably in the literature to describe a fibroblastic/myofibroblastic spindle cell proliferation with admixed inflammatory cells $[2,3,14,18]$. According to the World Health Organization's classification of tumors, the definition of IMT is a distinct borderline lesion composed of myofibroblastic cells with a variable admixture of inflammatory cells, and the terms IPT and IMT are considered synonymous [21]. It is difficult to diagnose an IPT or IMT because the lesions with the abovementioned histology exhibit highly variable and unpredictable clinical behavior [12].

Identification of chromosomal translocations of the $A L K$ gene located on chromosome $2 \mathrm{p} 23$ supports the hypothesis that IMTs are neoplastic in origin. Approximately $50 \%$ of IMTs show ALK positivity by FISH or immunohistochemistry or both [12]. The ALK-positive rate is reported slightly more frequently by immunohistochemical staining than FISH [22]. In addition, ALK expression in IMT is more common in younger patients [12]. However, among the reported pediatric laryngeal IMTs, only one showed immunoreactivity for ALK-1 protein [4]. In our case, both immunohistochemical and FISH analyses were positive for ALK protein expression and translocations involving the $A L K$ locus, respectively. So far, our case is the only laryngeal IMT that was confirmed to have the $A L K$ gene translocation at the molecular level.

ALK positivity confirmed that the IMT in our case was neoplastic. Could this have been the cause of the repeated tumor recurrence in our patient? We are not certain. The laryngeal IMT case reports followed a benign clinical course with rare local recurrences and were associated with a low rate of ALK positivity. Those IMTs that are negative for ALK may not be true neoplasms and thus have a better prognosis. However, among the children's laryngeal IMT reports, the only ALK-positive case had no recurrence, and the one recurrent case was ALK-negative [4,7]. In other anatomic locations, there are many reports of ALK-negative IMTs showing invasive biological behavior [23-25]. Accordingly, we think that complete resection of the tumor with negative surgical margins is the key to preventing recurrence. In the last operation for our case, frozen sections were performed to ensure negative surgical margins, and there has been no recurrence for 2 years.

\section{Conclusions}

Pediatric laryngeal IMT is extremely rare. We present the first case of a pediatric laryngeal IMT with multiple recurrences and ALK positivity confirmed by FISH. Although most laryngeal IMTs have benign clinical behavior, complete surgical resection with negative tissue margins and frequent, regular follow-ups are necessary because the lesion has unclear pathogenesis and the capacity for recidivism.

\section{Abbreviations \\ ALK: Anaplastic lymphoma kinase; EBV: Epstein-Barr virus; FISH: Fluorescence in situ hybridization; HE: Hematoxylin-eosin; HHV-8: Human herpes virus-8; IHC: Immunohistochemistry; IMT: Inflammatory myofibroblastic tumor.}

\section{Competing interests}

The authors declare that they have no competing interests.

\section{Authors' contributions}

All authors participated in the conception and design of the study. CY He performed the clinical analysis and drafted the manuscript. GH Dong performed the experiments and prepared the figures. HG Liu supervised the study. All authors read and approved the final manuscript.

\section{Acknowledgments}

Written informed consent was obtained from the patient for publication of this case report and accompanying images. A copy of the written consent is available for review by the Editor-in-Chief of this journal. The study was kindly supported by the Beijing Health System's Training Project for Backbones (No. 2009-3-31). 
Received: 30 September 2013 Accepted: 19 February 2014

Published: 6 March 2014

\section{References}

1. Coffin CM, Fletcher JA: Inflammatory myofi broblastic tumour. In World Health Organization Classification of Tumours. Edited by Fletcher CD, Unni KK, Mertens F. Lyon: Pathology and genetics of tumours of soft tissue and bone. IARC Press; 2002:91-93.

2. Coffin CM, Watterson J, Priest JR, Dehner LP: Extrapulmonary inflammatory myofibroblastic tumor (inflammatory pseudotumor). A clinicopathologic and immunohistochemical study of 84 cases. Am J Surg Pathol 1995, 19:859-872

3. Ong HS, Ji T, Zhang CP, Li J, Wang LZ, Li RR, Sun J, Ma CY: Head and neck inflammatory myofibroblastic tumor (IMT): evaluation of clinicopathologic and prognostic features. Oral Oncol 2012, 48:141-148.

4. Gutiérrez-Jodas J, Ruiz-Molina I, Jurado-Ramos A, Navarro JMC, Ramirez-Ponferrada R, Solis-Garcia E, Baños EC: Inflammatory myofibroblastic tumor of the subglottis in children-Report of a single case with positive anaplastic lymphoma kinase. Int J Pediatr Otorhinolaryngol Extra 2011, 6:195-197.

5. Kumar S, Gupta AK, Kakkar N: Inflammatory myofibroblastic tumor larynx mimicking laryngeal papillomatosis. Int J Pediatr Otorhinolaryngol Extra 2009, 4:42-44

6. Hartl T, Moxham JP, Ludemann JP, Rassekh SR: Inflammatory myofibroblastic tumour of the subglottis in a 5-year-old. J Otolaryngol Head Neck Surg 2009, 38:E104-E106.

7. Rodrigues M, Taylor RJ, Sun CC, Wolf JS: Inflammatory myofibroblastic tumor of the larynx in a 2-year-old male. ORL J Otorhinolaryngol Relat Spec 2005, 67:101-105

8. Hanna SJ, Blenke E, Sharma R, Knight LC: Laryngeal inflammatory pseudotumour: An unusual cause of airway obstruction. Int J Pediatr Otorhinolaryngol 2005, 69:1253-1255.

9. Munoz A, Villafruela M: Inflammatory pseudotumor of the larynx: MR findings in a child. Pediatr Radiol 2001, 31:459-460.

10. Zapatero J, Lago J, Madrigal L, Baschwitz B, Perez RE, Penalver R, Candelas J: Subglottic inflammatory pseudotumor in a 6-year-old child. Pediatr Pulmonol 1989, 6:268-271.

11. Keen M, Cho HT, Savetsky L: Pseudotumor of the larynx-an unusual cause of airway obstruction. Otolaryngol Head Neck Surg 1986, 94:243-246.

12. Gleason BC, Hornick JL: Inflammatory myofibroblastic tumours: where are we now? J Clin Pathol 2008, 61:428-437.

13. Lewis JT, Gaffney RL, Casey MB, Farrell MA, Morice WG, Macon WR: Inflammatory pseudotumor of the spleen associated with a clonal Epstein-Barr virus genome. Case report and review of the literature. Am J Clin Pathol 2003, 120:56-61.

14. Gomez-Roman JJ, Sanchez-Velasco P, Ocejo-Vinyals G, Hernandez-Nieto E, Leyva-Cobian F, Val-Bernal JF: Human herpesvirus-8 genes are expressed in pulmonary inflammatory myofibroblastic tumor (inflammatory pseudotumor). Am J Surg Pathol 2001, 25:624-629.

15. Stone JH, Zen Y, Deshpande V: IgG4-related disease. N Engl J Med 2012, 366:539-551.

16. Saab ST, Hornick JL, Fletcher CD, Olson SJ, Coffin CM: IgG4 plasma cells in inflammatory myofibroblastic tumor: inflammatory marker or pathogenic link? Mod Pathol 2011, 24:606-612.

17. Idrees MT, Huan Y, Woo P, Wang BY: Inflammatory myofibroblastic tumor of larynx: a benign lesion with variable morphological spectrum. Ann Diagn Pathol 2007, 11:433-439.

18. Alaani A, Hogg R, Warfield AT, Olliff J, Jennings C: Air bag injury as a cause of inflammatory myofibroblastic pseudotumour of the subglottic larynx progressing to myositis ossificans. Acta Otolaryngol 2005, 125:674-677.

19. Guilemany JM, Alos L, Alobid I, Bernal-Sprekelsen M, Cardesa A: Inflammatory myofibroblastic tumor in the larynx: clinicopathologic features and histogenesis. Acta Otolaryngol 2005, 125:215-219.

20. Vecchio GM, Amico P, Grasso G, Vasquez E, La Greca G, Magro G: Post-traumatic inflammatory pseudotumor of the breast with atypical morphological features: a potential diagnostic pitfall. Report of a case and a critical review of the literature. Pathol Res Pract 2011, 207:322-326.

21. Wenig BM: Inflammatory myofibroblastic tumour. In World Health Organization: classification of tumors. Pathology and genetics of Head and Neck tumours. Edited by Barnes L, Eveson JW, Reichart P, Sidransky D. Lyon: IARC Press; 2005:150-151.
22. Tothova Z, Wagner AJ: Anaplastic lymphoma kinase-directed therapy in inflammatory myofibroblastic tumors. Curr Opin Oncol 2012, 24:409-413.

23. Gale N, Zidar N, Podboj J, Volavsek M, Luzar B: Inflammatory myofibroblastic tumour of paranasal sinuses with fatal outcome: reactive lesion or tumour? J Clin Pathol 2003, 56:715-717.

24. Saleem MI, Ben-Hamida MA, Barrett AM, Bunn SK, Huntley L, Wood KM, Yelbuz TM: Lower abdominal inflammatory myofibroblastic tumor -an unusual presentation- a case report and brief literature review. Eur J Pediatr 2007, 166:679-683.

25. Yi XL, Lu HY, Wu YX, Li WH, Meng QG, Cheng JW, Tang Y, Liu Y, Bai XZ: Inflammatory myofibroblastic tumor with extensive involvement of the bladder in an adolescent: a case report. World J Surg Oncol 2013, 11:206.

doi:10.1186/1477-7819-12-54

Cite this article as: He et al:: Recurrent laryngeal inflammatory myofibroblastic tumor with positive anaplastic lymphoma kinase mimicking recurrent respiratory papillomatosis: a case report. World Journal of Surgical Oncology 2014 12:54.

\section{Submit your next manuscript to BioMed Central and take full advantage of:}

- Convenient online submission

- Thorough peer review

- No space constraints or color figure charges

- Immediate publication on acceptance

- Inclusion in PubMed, CAS, Scopus and Google Scholar

- Research which is freely available for redistribution

Submit your manuscript at www.biomedcentral.com/submit
C Biomed Central 